\title{
Correlation between Military Character Strengths and Leaders of Character in Software Development Process among Computer Science Students
}

\author{
Suzaimah Ramli, Muslihah Wook, Aminulhaq Ghazali, Roziyah Ahmad, Norulzahrah Mohd Zainudin, \\ and Noor Afiza Mat Razali
}

\begin{abstract}
The National Defence University of Malaysia (NDUM) is the sole provider of tertiary education for future military personnel. As a boutique university, NDUM emphasises on developing military character strengths among its students in all aspects of co-curricular and academic curriculum. This paper will present the relationship between Military Character Strengths (MCS) and the software development process (SDP), as part of the Final Year Project (FYP) for Computer Science students at the Faculty of Defence Science and Technology. This study has analysed the formation of an outstanding and successful NDUM student, which can be influenced by the MCS. NDUM has outlined the characteristics of its ideal graduates, known as the 'Leaders of Character' (LoC). The results showed that MCS are important attributes of LoC implementation. The results further showed that there was a correlation between MCS and LoC in software development process for Computer Science students in NDUM.
\end{abstract}

Index Terms-Military character strengths, software development process, military education, leaders of character, NDUM.

\section{INTRODUCTION}

NDUM was formerly known as Akademi Tentera Malaysia (ATMA) or the Malaysian Armed Forces Academy, which was established on June 1, 1995. This institution has also been branded as the sole organisation responsible for upgrading the knowledge and academic status of the armed forces by offering bachelor's degrees in engineering, sciences, and managements, while fulfilling the basic requirements of military training. NDUM prepares the Malaysian military and civilian leaders to better address national and international security challenges through multi-disciplinary educational programmes, research, professional exchanges, and outreach. The ultimate mission of this university is to develop a graduate who is an Intellectual Leader of Character (LoC). Students who participated in this study were assessed based on six attributes of LoC, namely, a graduate officer, a commissioned officer, a sports person, an imam, a master in self-defence, and an officer and a gentleman or a lady. Cadets

Manuscript received March 6, 2020; revised May 28, 2020.

Suzaimah Ramli, Muslihah Wook, Aminulhaq Ghazali, Roziyah Ahmad, Norulzahrah Mohd Zainudin, and Noor Afiza Mat Razali are with the Department of Computer Science, Faculty of Defence Science and Technology, National Defence University of Malaysia (e-mail: suzaimah@upnm.edu.my,muslihah@upnm.edu.my, haqa8944@gmail.com roziyah@mod.gov.my,

noorafiza@upnm.edu.my). at the NDUM undergo their academic and military training concurrently [1]. NDUM educates cadets to serve as officers in the Malaysian Armed Forces (MAF). Civilian students and those in the Reserve Officer Training Unit (ROTU) also have the opportunity to be absorbed into the MAF as graduate officers. To do so, specific military strengths and characteristics are required. By applying assumptions and formulations based on the taxonomy of 24 character strengths by Peterson and Seligman, previous studies have identified 12 relevant and important character strengths for success in the Norwegian army [2]. However, this study had only chosen four MCS that would apply to NDUM students.

To meet the requirements for graduation, the Computer Science students were asked to develop a complete software and report thesis as their Final Year Project (FYP). The main objective of this study was to determine whether character strength values exist and whether they are applied when the students are trying to solve problems in their formal learning. Formal learning here means that character strength values are correlated with the leaders of character attributes in software development process for their Final Year Projects. For example, NDUM students often find it easier to work in a group and follow the leader since the concept of teamwork and leadership is widely applied in the life of a cadet officer. For ROTU students and civilian students, this study also sought to investigate whether they were similarly influenced by these military values since their work do not differ much from that of student cadets.

\section{RESEARCH BACKGROUND}

\section{A. Military Character Strengths (MCS)}

The Norwegian Military Academy (NMA) educates cadets to serve as officers in international military operations. To do so, specific personal strengths and characteristics are required. By applying assumptions and formulations based on Peterson and Seligman's [2] taxonomy of 24 character strengths, previous studies have identified 12 relevant and important character strengths for success in the Norwegian army. These are: leadership, integrity, persistence, bravery, teamwork, fairness, open-mindedness, social intelligence, love of learning, perspective, self-regulation, and creativity. This research chose only four characters that closely relate to the aspiration and ultimate mission of NDUM, which is to develop LoC during software development process. The following sections will describe all four character strengths. 


\section{1) Leadership}

The military leadership literature is stratified into the frameworks, organizational, and coordinate levels of administration with an examination of thinking about on the basic errands and parsing capabilities required at each level [3]. Leadership is one of the various subjects within the educational programs designed for future officers [4]. The objective is to educate cadets with military and leadership abilities that they can apply accordingly in different situations and settings. The academic learning and teaching trajectory of a bachelor's program for cadets would include three bearings, namely, war studies, military management studies, and military frameworks and innovation [3].

\section{2) Creativity}

Creativity refers to a person's affiliation with information hubs, in this case, the wide domain of information actuation. This characteristic is the key component in the effective planning, preparation, and execution of a combat activity, and eventually, in winning a war. Creativity can be characterised as one's capacity to utilise something to create novel solutions. Simply put, creativity is one's ability to assess and use existing thoughts or forms in a diverse way. Creativity of commanders refers to their capacity to discover workable, novel solutions to problems - to be innovative and versatile in fast-paced and possibly confusing circumstances [5]. All famous military leaders have had an expansive degree of creative skills [6].

\section{3) Integrity}

Integrity could be an individual's virtue with social strings connected in relation to having solidarity of character. This infers consistency and steadfastness in convictions and actions. An individual with integrity carries her or his ethical convictions and values in her or his actions consistently, irrespective of outside pressures or temptations. Integrity, in some occasions, has been linked to trustworthiness, dependability, decency, honesty, and faithfulness.

\section{4) Teamwork}

McIntyre and Salas (in press) expressed that teamwork behaviour would include common execution checking, reinforcement behaviour, intra team criticism, and a conviction among individuals that their victory depends on their interaction [7], [8].

\section{B. Leaders of Character ( $L o C$ ) NDUM}

All NDUM students will be assessed based on six attributes of Leaders of Character, namely, as a graduate officer, a commissioned officer, a sports person, an imam, a master in self-defence, and lastly, an officer and a gentleman or a lady [9].

\section{1) Commissioned officer}

A Cadet Officers must be commissioned into the MAF services by His Royal Highness the King. A candidate for Cadet Officer will be assessed on academic results, physical and mental fitness, discipline, leadership and military skills. A Cadet Officer must obtain a minimum CGPA of 2.70, as stated in the agreement, to study and train at NDUM. A Cadet Officer is also required to undergo general military training at every semester carried out at the Military Training Academy.

\section{2) Master in self-defence}

It is important for NDUM students to obtain a black belt in Silat or Taekwondo. The art of self-defence builds personal character, promotes the traditional spirit of a warrior, trains different techniques in fighting, improves attitude, and can help with students' spiritual development.

\section{3) Sports person}

Being involved in sports can help build a strong body and a healthy mind, in addition to promoting unity among a multi-racial community. Sports activities at institutions of higher learning (IHL) can project the image of a university at the national and international levels. The philosophy of sports can also help students to manage their time between learning and participating in sports.

\section{4) Spiritual leader}

Developing imams and religious leaders through courses at NDUM is a tangible way to develop a Leader of Character. Students who display the attributes of a spiritual and religious leader would also gain the respect of other students. As a Muslim, he will be the imam for Friday prayers, whereas a non-Muslim student will lead pray and worship in his/her religion.

\section{5) An officer and a gentleman or lady}

NDUM has the important role of moulding courteous and well-mannered students into officers and a gentleman or a lady, so as to be aligned with the National Education Philosophy.

\section{Software Development Process (SDP)}

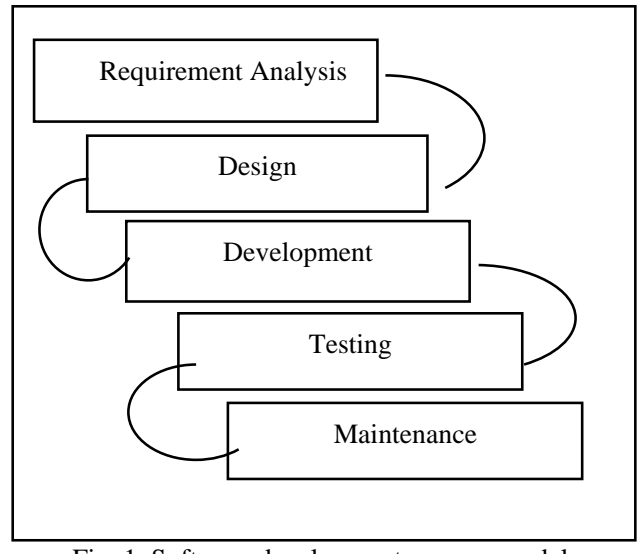

Fig. 1. Software development process model.

Software development Process model (Fig. 1) are utilised for the advancement of software projects. These model represent the sequence of stages and exercises that would take place during software advancement. An SDP model would consist of seven phases, namely, requirements, analysis, design, development testing, and maintenance [10]. The waterfall model, the spiral model, the incremental model, the rapid prototyping model, and the agile model are some of the most successful SDP models available [11], [12].

\section{Final Year Project}

The final year project gives students the chance to demonstrate the knowledge and skills they have developed throughout their study in the Computer Science programme. Students can take this opportunity to develop a complete software project life cycle under the guidance of a supervisor. 
At the end of the semester, each student is required to submit a final year project report and to present this project to both his/her supervisor and several assessors for assessment. All students are required to complete their Final Year Project to graduate. The total credit point is 120 credits, while a Final Year Project is worth 12 credits.

\section{CONCEPTUAL MODEL}

Based on previous studies, the following conceptual model is designed to look at the correlation between MCS to LoC in SDP as shown in Fig. 2.

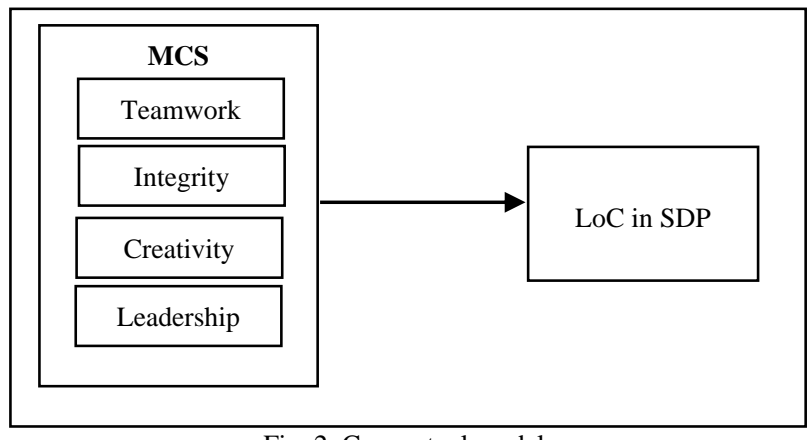

Fig. 2. Conceptual model.

\section{Methodology}

\section{A. Participants}

This study has selected 31 students from the Department of Computer Science, Faculty of Defence Science and Technology, NDUM. The students were divided into three groups, namely, Cadets consists of 12 participants, ROTU (Reserve Officer Training Unit) consists of eight participants, and Civilians with 11 participants. These students were all enrolled in a three-year bachelor's programme in Computer Science. Cadets will have extra weight because they will be commissioned to the rank of lieutenant.

\section{B. Learning Environment}

Each group was given three different case studies that they have to solve. Prior to participating in the case study session, these students were taught the theory of Software Development. Concurrently, they were briefed on the purpose of this study and were given a short lecture on character strengths.

\section{Experimental Procedures}

The experimental procedures are detailed as follows:

1) Students were asked to attend the Software Development theory classes for 4 hours of lectures and 2 hours of tutorials.

2) The research procedure was explained to the students.

3) The students were divided according to their type, which were Cadet, ROTU, and Civilians.

4) Three different case studies were given to each group to be solved.

5) Questionnaires were distributed to the students.

6) Students submitted their reports.

7) Students presented their findings.

The questionnaire was implemented to confirm that MCS were embedded in the software development process. The goal of the questionnaire was to determine the view of the respondents on the importance of MCS, which were applied during the requirement analysis for their software development. This questionnaire included 22 basic statements (claims) to which the respondents were asked to answer by selecting their level of agreement or disagreement, according to the prescribed scale. The following scale defines five basic statements:
1) Strongly disagree
2) Disagree
3) Neither agree nor disagree
4) Agree
5) Strongly agree

\section{DATA ANALYSIS AND RESUltS}

There were no correct or wrong answers in the questionnaire. The questions were used to express the views of the respondents regarding the importance of MCS throughout the process of software development. MCS could ensure that the developed software meets the requirements of the users, as well as being more user-friendly. This preliminary study used three stages of data analysis process: (i) descriptive statistics; (ii) normality of data distribution and reliability analysis; and (iii) correlation analysis. The descriptive statistics was conducted to describe the demographics of the respondents and the variables. Then, the normality of data distribution was assessed by calculating the skewness and kurtosis values. The reliability values for each variable were analysed using the Cronbach's alpha value. Finally, the correlation for all variables were analysed using the Pearson product-moment correlation analysis.

\section{A. Descriptive Statistics}

The descriptive statistics of respondents' demographic are presented in Table I.

TABLE I: DEMOGRAPHIC OF RESPONDENTS

\begin{tabular}{lcc}
\hline \hline Descriptions & Frequency & Percentage \\
\hline Gender: & 21 & 67.7 \\
Male & 10 & 32.3 \\
Female & 31 & 100 \\
Total & & \\
\hline Category of Student: & & \\
Cadet & 12 & 38.7 \\
ROTU & 8 & 25.8 \\
Civilian & 11 & 35.5 \\
Total & 31 & 100 \\
\hline \hline
\end{tabular}

Table I shows that $21(67.7 \%)$ male and $10(32.3 \%)$ female respondents are involved in this study. The respondents consisted of 12 cadets $(38.7 \%), 8$ ROTU $(25.8 \%)$, and 11 civilian students $(35.5 \%)$. Meanwhile, the descriptive statistics for each variable are shown in Table II.

TABLE II: DESCRIPTIVE STATISTICS OF VARIABLES

\begin{tabular}{llcc}
\hline \hline No. & Variable & Mean & Standard Deviation \\
\hline 1. & Teamwork & 4.72 & 0.40 \\
2. & Integrity & 4.19 & 0.59 \\
3. & Creativity & 4.19 & 0.70 \\
4. & Leadership & 4.49 & 0.42 \\
5. & LoC in SDP & 4.15 & 0.70 \\
\hline \hline
\end{tabular}


Based on the 31 responses, the mean ranged between 4.15 and 4.72 , while the standard deviations were between 0.40 and 0.70 , indicating that all variables recorded nearly high scores.

\section{B. Normality of Data Distribution and Reliability Values}

The normality of data was assessed through skewness and kurtosis values, as suggested in [13]. The skewness value should be less than 3 , while the kurtosis value should be less than 10. Some studies indicated that both skewness and kurtosis should range within \pm 1.96 [14], while others stated that these values should range within \pm 2 [15]. Table III shows the analysis results of the normality of data distribution for each variable through the range of skewness and kurtosis values. The results showed that skewness values ranged from -1.15 to -0.57 , while the kurtosis values ranged from -0.09 to 0.39 . Hence, the normality of data distribution in this study was confirmed since each variable was within the acceptable range of both skewness and kurtosis values.

TABLE III: RESULTS OF NORMALITY DISTRIBUTION

\begin{tabular}{llcc}
\hline \hline No. & Variables Name & Skewness & Kurtosis \\
\hline 1. & Teamwork & -1.15 & -0.09 \\
2. & Integrity & -0.57 & 0.05 \\
3. & Creativity & -0.73 & 0.39 \\
4. & Leadership & -0.80 & 0.34 \\
5. & LoC in SDP & -0.72 & 0.13
\end{tabular}

Note: Standard Error in Skewness is 0.421; Standard Error in Kurtosis is 0.821

The following Table IV shows the results of reliability values. The acceptable minimum value of Cronbach's alpha is 0.60 [16], [17], and a value of higher than 0.80 is preferable [13], [18]. The Cronbach's alpha of 'leadership' was 0.51, which must be eliminated. However, 'teamwork', 'integrity', 'creativity', and 'SDP' were reliable as all these values were higher than 0.60 , ranging from 0.69 to 0.87 . Therefore, the results of these variables were reliable and consistent.

TABLE IV: RESULTS OF RELIABILITY VALUES

\begin{tabular}{llcc}
\hline \hline No. & Variables Name & Number of Items & Cronbach Alpha \\
\hline 1. & Teamwork & 6 & 0.86 \\
2. & Integrity & 4 & 0.69 \\
3. & Creativity & 5 & 0.87 \\
4. & LoC in SDP & 5 & 0.76 \\
5. & Leadership & 5 & 0.51 \\
\hline \hline
\end{tabular}

\section{Correlation Analysis}

Pearson's two-tailed bivariate was applied to obtain the correlations within each variable setting. Results of the correlation analysis are shown in Table V.

TABLE V: RESULTS OF CORRELATION ANALYSIS

\begin{tabular}{lcccc}
\hline \hline Variables & T & I & C & S \\
\hline Teamwork (T) & 1 & - & - & - \\
Integrity (I) & 0.248 & 1 & - & - \\
Creativity (C) & $0.362^{*}$ & $0.627^{* *}$ & 1 & - \\
LoC in SDP (S) & 0.033 & $0.550^{* *}$ & $0.562^{* *}$ & 1 \\
\hline \hline
\end{tabular}

Note: * significant at $0.05, * *$ significant at 0.01

All variables have correlation value within the acceptable range of \pm 0.70 [13]. 'Creativity' was found to be highly correlated to 'integrity', 'SDP' and 'teamwork' at 0.627 , 0.562 , and 0.362 , respectively. This is because integrity is an important principle for a cadet as well as other students. The application of integrity features is emphasized in every military activity and training for cadets. NDUM students also need to be creative in developing a quality software and running across the user's demands. Nevertheless, low correlations were noted between 'teamwork' and 'SDP' at 0.033 , as well as between 'teamwork' and 'integrity' at 0.248 . This low correlation because the low number of respondents due to the intake for this batch of computer science majoring artificial intelligence were only 40 students.

\section{CONCLUSION}

The findings of the study clearly indicate that all the stated objectives are met. These findings showed that the correlation between 'creativity' and 'integrity' needs to have more attention at the requirement analysis phase. These two variables are interrelated and can help students to create software that would better serve the requirements of the users. To relate MCS with NDUM's LoC, validation tests must be conducted to explore how MCS could help students to produce high quality software for their FYPs. Future works are encouraged to increase sampling size and performed other analysis.

\section{CONFLICT OF INTEREST}

The authors declare no conflict of interest.

\section{AUTHOR CONTRIBUTIONS}

Suzaimah and Muslihah led the research, analyzed the data and wrote the article; Aminul and Roziyah conducted the preliminary data collection and carried out the experiments; Norulzahrah and Noor Afiza reviewed and improved the paper; all authors had approved the final version.

\section{ACKNOWLEDGMENT}

The authors would like to acknowledge the Third Year Computer Science Students majoring Artificial Intelligence, 3TSI1, 3TSI2, and the National Defence University of Malaysia for supporting this project.

\section{REFERENCES}

[1] J. Juhary, "Understanding military pedagogy," Procedia Social and Behavioral Sciences, 2014.

[2] C. Peterson and M. E. P. Seligman, "Evaluating character strengths in cadets during a military field exercise: Consistency between different evaluation sources," A Handbook and Classification, 2004.

[3] L. Wong, P. Bliese, and D. McGurk, "Military leadership: A context specific review," The Leadership Quarterly, vol. 14, no. 6, pp. 657-692, Dec. 2003.

[4] W. Klinkert, M. T. I. B. Bollen, M. Jansen, H. Jong, E.-H. Kramer, and L. Vos, NL ARMS Netherlands Annual Review of Military Studies 2019: Educating Officers: The Thinking Soldier - the NLDA and the Bologna Declaration, 2019.

[5] M. Vego, "On military creativity," Ndupress, no. 70, pp. 83-90, 2013.

[6] F.-C. Chiu and P. L.-P. Tu, The Priming Effect of Military Service on Creativity Performance, p. 21, 2014.

[7] P. Robinson, "Magnanimity and integrity as military virtues," Routledge, vol. 6, p. 12, Dec. 2007.

[8] E. Salas, C. A. Bowers, and J. A. Cannon-Bowers, "Military team research: 10 years of progress," Military Psychology, vol. 7, no. 2, pp. 55-75, Jun. 1995. 
[9] M. R. Zulkifly, J. W. Tang, I. Sarah, A. R. Ainul, R. Afiqah, and M. S. Afizi, "Leader of character framework for bachelor degree in maritime," Science Publishing Corporation, vol. 7, no. 429, pp. 208-212, 2018

[10] A. Bahattab and A. Alshamrani, "A comparison between three SDLC models," International Journal of Computer Science Issues, vol. 12, no. 1, pp. 106-111, Jan. 2015.

[11] A. Y. Egwoh and O. F. Nonyelum, "A software development life cycle model for improved students' communication and collaboration," International Journal of Computer Science \& Engineering Survey (IJCSES), vol. 8, no. 4, pp. 1-10, Aug. 2017.

[12] O. Veysi, "Selection of appropriate software development life cycle using fuzzy logic," Journal of Intelligent Fuzzy Systems, no. 3, pp. 797-810, 2013.

[13] J. F. Hair, W. C. Black, B. J. Babin, and R. E. Anderson, Multivarite Data Analysis: A Global Perspective, 7th ed. Upper Saddle River: Pearson Education, 2010

[14] C. Y. Piaw, Asas Statistik Penyelidikan, 2nd ed. Malaysia: McGraw Hill Education, 2012

[15] T. J. B. Kline, Psychological Testing: A Practical Approach to Design and Evaluation, 3rd ed. Thousand Oaks, CA: SAGE, 2005.

[16] J. F. Hair, M. Sarstedt, L. Hopkins, and V. G. Kuppelwieser, "Partial least squares structural equation modeling (PLS-SEM): An emerging tool in business research," European Business Review, vol. 26, no. 2, pp. 106-121, 2014.

[17] J. Henseler, C. M. Ringle, and R. R. Sinkovics, "The use of partial least squares path modeling in international marketing. Dlm. Henseler Ringle \& Sinkovics (pnyt.)," Advances in International Marketing, pp. 277-319, 2009

[18] J. Pallant, SPSS Survival Manual: A Step by Step Guide to Data Analysis Using SPSS, 4th ed. NSW, Australia: Allen \& Unwin, 2011, p. 359.

Copyright $\odot 2020$ by the authors. This is an open access article distributed under the Creative Commons Attribution License which permits unrestricted use, distribution, and reproduction in any medium, provided the original work is properly cited ( $\underline{\text { CC BY 4.0) }}$.

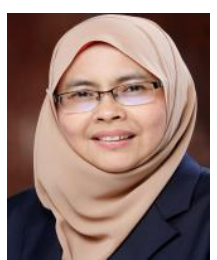

Suzaimah Ramli was born in Temerloh Pahang. She received her $\mathrm{PhD}$ in electrical, electronic and system engineering from Universiti Kebangsaan Malaysia in 2011, master of computer science from Universiti Putra Malaysia in 2001, and bachelor of information technology (hons) from Universiti Utara Malaysia in 1997. Her research interests include image processing and artificial intelligence applications in various domain particularly in education, security and defence. Currently she is working as an associate professor at Department of Computer Science, Faculty of Defence Science and Technology, National Defence University of Malaysia. She is a member of Malaysia Board of Technologist and Informatics Intelligence Special Interest Group, UPNM. She has published and presented most of her research findings to various international conferences and articles in many international journals specifically in her research niche.

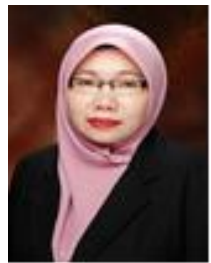

Muslihah Wook was born in Batu Gajah, Perak. She received her $\mathrm{PhD}$ in information science from Universiti Kebangsaan Malaysia in 2017, master of computer science from Universiti Putra Malaysia in 2004, and bachelor of information technology (hons) from Universiti Utara Malaysia in 2001. Her research interests include data mining applications in various domain particularly in education, security and defence. Currently she is working as a senior lecturer at Department of Computer Science, Faculty of Defence Science and Technology, National Defence University of Malaysia. She has become a member of International Association of Computer Science and Information
Technology (IACSIT) and Institute of Research Engineers and Doctors (IRED) since 2011 and 2013 respectively. Recently, she has been appointed as a technical reviewer of Education and Information Technologies-Springer's journal indexed by Scopus (Q2).

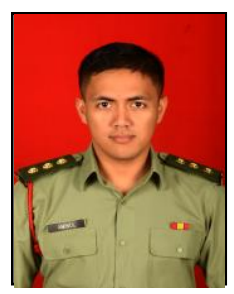

Kapt Mohammad Aminul Haq bin Mohd Ghazali is a staff officer 3 at Administration Department of Military Training Academy, that is an academy under National Defence University of Malaysia also known as UPNM. He obtained his bachelor degree in computer science majoring in artificial intelligence from UPNM in 2012. He currently is pursuing his master of computer science at UPNM. He has experience in military tactics based on his involvement during operation and exercise with the infantry troops. $\mathrm{He}$ is an experienced instructor that is responsible to educate UPNM cadets the knowledge of basic military skills.

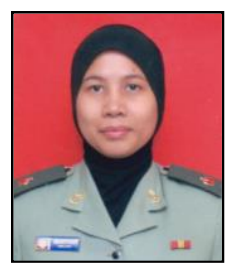

Roziyah binti Ahmad is a military officer in Ministry of Defence, Malaysia. She received her PhD in civil engineering and structural from Universiti Kebangsaan Malaysia in 2019, MSc in building technology (2002) and BSc in engineering and building science (1999) both from Universiti Sains Malaysia, Pulau Pinang.

Her research interests are primarily in sustainable material and its applications in construction industry, green building index and building information modelling. Her current research is involving natural fiber reinforcement in cementitious building materials. She also involved in structural design, consultation, and monitoring for National Blue Ocean Strategy (NBOS) and in house project under Armed Forces at Ministry of Defence. She has published and presented her research findings to international conferences and articles in international journals specifically in her research niche.

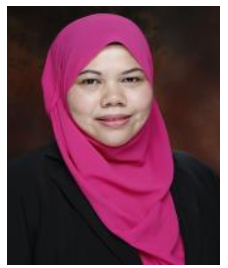

Norulzahrah Mohd Zainudin is a lecturer in the Department of Computer Science at Faculty of Defence Science and Technology, National Defence University Malaysia (UPNM). She received her MSc at Universti Putra Malaysia and joined Military Academy of Malaysia in 2002. Her main research interests are in the areas of forensic computing, online social networks and computer intelligence. She has published a number of papers in international journals and conferences. Currently she is a member of Informatics Intelligence Special Interest Group, UPNM.

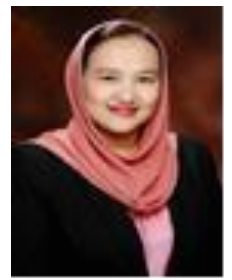

Noor Afiza Mat Razali holds a bachelor's degree in computer and information engineering, master of science in computer science and $\mathrm{PhD}$. of science in computer science from Japanese Universities. Afiza is a senior lecturer at the Defence Science an Technology Faculty in National Defence University of Malaysia. Afiza also was appointed as a visiting lecturer and fellow at Management and Science University Malaysia, Academic Liaison Consultant for Japanese Universities at University Kuala Lumpur and fellow at Education Malaysia Global Services (EMGS). Afiza research and expertise are in the area of cyber security, disaster management system, big data analytics, human computer interaction, artificial intelligence \& robotics and blockchain technology. Afiza also a professional technologist, a recognition given by Malaysia Board of Technologist. 